\title{
HYPERKALAEMIA IN TRAUMATIC RENAL FAILURE
}

\author{
Report of Two Cases \\ Kenneth S. Morton and Frank P. Patterson, Vancouver, Canada \\ From the Department of Orthopaedic Surgery, Vancouver General Hospital, \\ and the Faculty of Medicine, University of British Columbia
}

Surprisingly little mention has been made in the orthopaedic literature of the elevation of serum potassium in post-traumatic acute renal failure. The importance of this complication of trauma is indicated by Teschan, Post et al. (1955) in quoting Mallory's figure of 18.6 per cent renal deaths in 427 battle casualties; Simeone's of 14 per cent of deaths in 165 necropsies in Korean casualties; and a group of patients severely wounded in the second world war of whom 40 per cent developed acute renal failure. These authors themselves found, in 8,000 Korean casualties, an incidence of acute renal failure of 0.5 per cent; but in a severely wounded group of forty-three casualties this incidence rose to 21 per cent. The frequency and rapidity of development of potassium intoxication was striking in their cases; death from cardiac arrest of potassium intoxication occurred as early as the fourth day. Of seventy-two dialyses carried out in treatment, fifty were done for hyperkalaemia alone or for hyperkalaemia with uraemia (Smith, Post et al. 1955).

That the condition is also encountered in civilian practice is recorded by Swann and Merrill (1953), who summarised current knowledge of acute renal failure and stated their experience with eighty-five cases. Hyperkalaemia occurred in most of their cases, and frank potassium intoxication in 25 per cent.

Recently we have encountered two cases in which potassium rose to alarmingly high levels, such that death from its cardiotoxic effect was threatened. In both cases the question of surgical treatment by evacuation of a large haematoma or ligation of large vessels from a damaged limb, as ready sources of free potassium, was debated.

\section{CASE REPORTS}

Case 1-A man aged thirty-two years suffered right above-knee and left below-knee traumatic amputations in a logging accident. First-aid and resuscitative measures were used before his admission to the Vancouver General Hospital on the third day. Oliguria was already apparent, the urine output averaging 500 cubic centimetres a day for these three days. He was conscious but confused. There was moderate oedema of the perineum, and marked swelling and ecchymosis of the right flank, hip and thigh. The blood pressure was $110 / 90$ millimetres Hg., pulse 96 per minute, haemoglobin 14.8 grammes per cent. The potassium was already elevated to $6.5 \mathrm{~m}$.Eq. per litre. Gas gangrene and tetanus antisera, penicillin and streptomycin were given. The mental state fluctuated between clarity and confusion. Urine output continued to be low, averaging 725 cubic centimetres for the next three days with an oral and parenteral fluid intake approaching two litres daily. Significantly, the specific gravity of the urine was recorded as 1.008 and 1.006 on two occasions and contained gross blood and 3 plus protein. Electrolyte determinations showed hypochloraemia and hyperkalaemia, and uraemia was evident (Table I). On the fifth day after the injury the blood pressure rose to $140 / 90$ millimetres $\mathrm{Hg}$. and the following day an attempted aspiration of the haematoma of the right flank failed. The original stump dressings were removed under cyclopropane anaesthesia. Both stumps required further cleansing and debridement and were packed open. Thrombosed anterior and posterior tibial vessels were noted in the below-knee stump. One litre of matched blood was given during the procedure, and the blood pressure remained between 130/75 and 160/90 millimetres $\mathrm{Hg}$. 
Immediately after the operation the patient's general condition improved and he was mentally clear, with a blood pressure of $150 / 85$ millimetres $\mathrm{Hg}$. and a pulse of 110 per minute. The next day he was restless, developed a cough, and was irrational. He became more difficult to nurse and, when turned on his side, became suddenly cyanotic and died, twenty hours after operation.

At necropsy, performed the day after death, there was a large haematoma in the right abdominal muscles, extending into the right thigh and across the pubis. All the superficial and deep veins were thrombosed except for their upper parts, which were free of clot.

TABLE I

Biochemical Investigations in Case 1

\begin{tabular}{|c|c|c|c|c|c|c|c|}
\hline $\begin{array}{c}\text { Day } \\
\text { after } \\
\text { injury }\end{array}$ & $\begin{array}{c}\text { Urine output } \\
\text { (cubic centimetres) }\end{array}$ & $\begin{array}{l}\text { Na m.Eq. } \\
\text { per litre }\end{array}$ & $\begin{array}{l}\mathrm{Cl} \text { m.Eq. } \\
\text { per litre }\end{array}$ & $\begin{array}{c}\mathrm{CO}_{2} \mathrm{~m} . \mathrm{Eq} . \\
\text { per litre }\end{array}$ & $\begin{array}{l}\mathrm{K} \text { m.Eq. } \\
\text { per litre }\end{array}$ & $\begin{array}{c}\mathrm{NPN} \\
\text { (milligrams } \\
\text { per cent) }\end{array}$ & $\begin{array}{c}\text { Creatinine } \\
\text { (milligrams } \\
\text { per cent) }\end{array}$ \\
\hline 3 & $? 405$ & 129 & 81 & 34 & 6.5 & 76 & $4 \cdot 4$ \\
\hline 4 & 690 & 132 & 82 & 29 & $6 \cdot 1$ & 111 & 5.8 \\
\hline 5 & 750 & 130 & 78 & 32 & $6 \cdot 1$ & 123 & $6 \cdot 7$ \\
\hline 6 & 725 & 134 & 84 & 25 & $6 \cdot 2$ & 123 & $7 \cdot 2$ \\
\hline 7 & 400 & & & & & & \\
\hline
\end{tabular}

The femoral arteries were thrombosed and there were irregular ischaemic changes in the muscles of the left leg. The lungs showed a recent organised thrombus partly obstructing the pulmonary artery and extending back into the right ventricle and auricle. The kidneys weighed 600 grammes and cortical pallor was noted. Microscopicaliy, the kidneys were described as typical of the so-called crush or shock kidney, with disruption of the tubules, eosinophilic granular debris in the capsular space and tubules, and tubular rupture with interstitial reaction. The pathological diagnoses were massive pulmonary embolus due to phlebothrombosis and thrombophlebitis of the right leg and renal tubular degeneration and disruption with early cortical necrosis.

Comment-Though this patient was not severely oliguric, the non-protein nitrogen and creatinine were elevated to 123 milligrams per cent and $7 \cdot 2$ milligrams per cent respectively, and he was undoubtedly in acute renal failure in consequence of the severe injury and subsequent prolonged hypotension. Urine volumes were, in fact, frequently in the neighbourhood of 600 to 700 cubic centimetres, but this urine was of poor quality, the specific gravity being only 1.006 to 1.008 . At such specific gravities, such volumes are entirely inadequate in disposing of toxic materials. A large haematoma in the right hip region was apparent, and when the serum potassium became elevated to $6.5 \mathrm{~m}$.Eq., the surgical evacuation of the potassium-laden mass was considered. Risk of infection delayed this procedure, and when the kalaemia levelled off at $6 \cdot 1 \mathrm{~m} . \mathrm{Eq}$., operation was felt to be unnecessary, though aspiration was attempted.

Case 2-A man aged twenty-two years was injured in a logging accident in 1954. When he was admitted to the Vancouver General Hospital three and a half hours after the injury his blood pressure was 60/35 millimetres $\mathrm{Hg}$., and the pulse 90 per minute. His left foot and leg lay in lateral rotation and the left thigh was much enlarged and tense. Sensation was absent at the left foot; a faint anterior tibial artery pulsation was described but the foot was pale and cyanotic.

Haemoglobin was 7.7 grammes per cent, haematocrit 28. Intravenous Subtosan and whole blood raised the blood pressure to $85 / 45$ millimetres $\mathrm{Hg}$. within half an hour, and to

VOL. $40 \mathrm{~B}$, NO. 1, FEBRUARY 1958 
105/65 millimetres $\mathrm{Hg}$. four hours after admission, but the pulse remained elevated to 120 per minute. Exploration of the left thigh vessels was considered, but, though the thigh became further enlarged and pulsation was not palpable, the foot was warmer and venous filling was noted; the operation was therefore not carried out. Routine antibiotics and antisera were given. No urine was obtained by catheterisation. On the first day after the injury he began vomiting, and the local swelling increased. Sensation was absent below the knee, and the left foot was cool. The urine output was 660 cubic centimetres. The specific gravity was not recorded, but examination for myoglobin was negative and for protein positive. The blood pressure had become constant at 120/70 millimetres $\mathrm{Hg}$.

On three occasions 15 cubic centimetres of 2 per cent Xylocaine were injected through an epidural catheter to improve the blood supply to the limb. The blood pressure fell as low as 80/60 millimetres $\mathrm{Hg}$. after the first of these injections. Ischaemic changes progressed, the foot became cyanotic and mottled, and the calf was swollen and hard. Non-protein nitrogen was elevated to 85 milligrams per cent and potassium to $7 \cdot 2 \mathrm{~m}$.Eq. (Table II). On this and the following days the fluid intake approached three litres daily.

TABLE II

Biochemical InVestigations in CASE 2

\begin{tabular}{|c|c|c|c|c|c|c|}
\hline $\begin{array}{l}\text { Day } \\
\text { after } \\
\text { injury }\end{array}$ & $\begin{array}{c}\text { Urine output } \\
\text { (cubic centimetres) }\end{array}$ & $\begin{array}{l}\text { Na m.Eq. } \\
\text { per litre }\end{array}$ & $\begin{array}{l}\mathrm{Cl} \text { m.Eq. } \\
\text { per litre }\end{array}$ & $\begin{array}{c}\mathrm{CO}_{2} \text { m.Eq. } \\
\text { per litre }\end{array}$ & $\begin{array}{l}\mathrm{K} \text { m.eq. } \\
\text { per litre }\end{array}$ & $\begin{array}{c}\text { NPN } \\
\text { (milligrams } \\
\text { per cent) }\end{array}$ \\
\hline \multicolumn{7}{|l|}{0} \\
\hline 1 & 660 & 140 & 96 & 28 & $7 \cdot 2$ & 85 \\
\hline 2 & 330 & & & 30 & & 83 \\
\hline 3 & 580 & 132 & 90 & 33 & $9 \cdot 2$ & 111 \\
\hline
\end{tabular}

On the second day the patient's condition remained static. The urine volume fell to 330 cubic centimetres with a specific gravity of 1.017. There was developing gangrene of the left foot. On the third day he became restless, hyperexcitable and confused; a sudden episode of dyspnoea and collapse responded well to intravenous Coramine and oxygen. An electrocardiograph showed changes characteristic of gross potassium intoxication. Potassium at this time was $9 \cdot 2 \mathrm{~m}$.Eq. and non-protein nitrogen 111 milligrams per cent. Consideration was given to ligation of the large vessels of the left thigh in an attempt to reduce the source of noxious substances. As an alternative, extra-corporeal dialysis was begun on the evening of the third day and continued for three hours.

Electrocardiographs during this period showed a progressive reversal of the potassium effect after seventy-five minutes of dialysis. The patient's general condition improved at first and the urine output increased, but ten hours after dialysis he suddenly collapsed and died on the morning of the fourth day after the injury.

At necropsy, performed the day of death, the right mid-thigh circumference was eighteen inches, the left twenty-seven inches. There was a fracture of the left femoral shaft, and the medial and posterior thigh muscles were completely stripped from the length of the femur. A cavity fifteen inches long and four inches in diameter, filled with blood, was thus formed. The femoral artery was torn at the supracondylar level and was constricted above and below this point. The femoral vein was ruptured just proximal to the tear in the artery.

Examination of the heart showed both ventricles to be dilated. The kidneys weighed 480 grammes, the cut surface bulged and the cortex was pale. Microscopically, cardiac muscle fibres were swollen, with some fragmentation. The kidney: congested glomerular tufts with increased capsular space; eosinophilic granular debris in this space and the tubules; loss of 
lining epithelium and rupture of tubules; interstitial reaction with mononuclear and foreign body giant cells.

The final pathological diagnosis was multiple pulmonary emboli from phlebothrombosis and thrombophlebitis in veins of the left leg, and "shock kidney."

Comment-This patient became oliguric and uraemic after the injury, which lowered the blood pressure to below 100 millimetres $\mathrm{Hg}$. (systolic) for a period of seven hours. A large source of potassium was evident clinically and at necropsy in the severely damaged thigh, and that potassium ions were in fact being freed into the circulation was evident from the characteristic electrocardiographic changes and biochemical determinations.

Less evident in this case is the fact that some degree of acute renal failure adds to the elevation of serum potassium. Though the urine volume fell as low as 330 cubic centimetres and the non-protein nitrogen rose to 111 milligrams per cent, the specific gravity of the urine remained at 1.011 to 1.017 . Nevertheless it is apparent that the two factors, increased source of potassium and decreased excretion of it by a failing kidney, contribute to the hyperkalaemia. Swann and Merrill (1953) stated that acute renal failure connot be ruled out by a urine specific gravity of 1.015 to 1.020 during the first week, and in some of their cases daily urine volumes were 400 to 800 cubic centimetres. There seems little doubt, therefore, that these kidneys were failing, and it seems possible that early radical sacrifice of the limb might have lessened the eventual hyperkalaemia. Such surgery, however, would be a difficult action to take when it is considered that, on the basis of ischaemic changes, a below-knee amputation would have sufficed. It is unlikely that ligation of vessels or late radical amputation would have affected the course of the illness favourably. Notable was the dilated heart found at necropsy; this is characteristic of the cardiotoxic effect of potassium but also of an overloaded heart, here possibly the result of dialysis.

\section{DISCUSSION}

That potassium has a cardiotoxic effect has been shown by Winkler, Hoff and Smith (1941), and the electrocardiographic changes in hyperkalaemia have been described by Hoff, Smith and Winkler (1941), Derot, Pignard, Touraine and Bernard (1953), and Strauss (1948). Hoff $e t$ al. also pointed out that serum potassium does not reach this toxic level in experimental acute renal failure nor in chronic renal failure because of the high clearance of potassium. In fact, Muirhead and Hill (1948) stated that a daily intake of 0.5 to 1.0 gramme of potassium during the renal insufficiency phase of acute renal failure will not produce hyperkalaemia, and Platt (1953) found that, even when the glomerular filtration rate was reduced to 20 per cent of normal, the daily excretion of potassium remained normal.

Smith (1951) also referred to the fact that potassium is completely filtrable. Nevertheless, the cardiotoxic effect of potassium has been consistently described by several authors (Allen 1952; Balch, Meroney and Sako 1955; Burnett et al. 1947; Derot et al. 1953; Hicks, Crutchfield and Wood 1950; Humphrey and Avery Jones 1947; Knowles and Kaplan 1953; Stock 1949; Strauss 1948) as a precipitating cause of death in many cases of uraemia.

It seems necessary, therefore, to look for an intrinsic source of excess potassium to account for these clinical observations: a ready source is the intracellular component of body fluid. The intracellular concentration of potassium has been determined to be 115 to 160 m.Eq. per litre (Derot et al. 1953) and much can be released into the circulation by injury (Green 1945), prolonged ischaemia (Rewell 1943, Meroney and Herndon 1954) and catabolic processes (Balch, Meroney and Sako 1955; Derot et al. 1953). The small daily quantity of potassium from catabolism is easily excreted and may accumulate for weeks in anuria without reaching toxic levels. But in post-traumatic conditions there is excessive loss from damaged cells, devitalised tissue giving up potassium to the plasma (Fenn 1940).

Detection of dangerously elevated potassium levels must rely entirely on biochemical determinations and electrocardiographic examinations. The electrocardiograph shows the effects of potassium intoxication first (Meroney and Herndon 1954, Teschan et al. 1955, 
Keith and Burchell 1949), and clinical signs such as paraesthesiae and flaccid paralysis appear only as terminal manifestations. It should be noted, too, that the cardiotoxic effects of potassium become apparent at variable serum levels, being dependent also on the calcium, phosphate and sodium levels (Meroney and Herndon 1954, Teschan et al. 1955).

One facet of the successful management of acute renal failure would, therefore, appear to be the control of hyperkalaemia. Early attention, in this regard, was paid to removal of the source by primary amputation, fascial incisions and gradual tourniquet release from pressure (Belsey and McMichael 1942), but recently medical means have been employed to remove excess potassium already in circulation. These have included extracorporeal and corporeal dialysis (Balch et al. 1955; Hicks et al. 1950; Meroney and Herndon 1954; Smith et al. 1955), cation exchange resins (Derot et al. 1953; Knowles and Kaplan 1953; Meroney and Herndon 1954) and hypertonic glucose with insulin (Allen 1952; Derot et al. 1953; Meroney and Herndon 1954; Smith et al. 1955). In one of the two cases reported above, dialysis in the Kolff dialyser was successful in relieving the potassium effect on the heart, as shown by reversal of the electrocardiographic changes. However, the patient died in spite of this success, possibly from multiple pulmonary emboli or pulmonary oedema. Dialysis is notably not without danger.

In both cases the question of surgical removal of a large source of potassium was raised. Smith et al. (1955), in their review of fifty-one cases of renal insufficiency in Korean battle casualties, concluded that radical debridement, early amputation of gangrenous parts and drainage of infected foci were essential, often blunting the rapid progress of uraemia. The danger of infection and of further shock is not negligible in the evacuation of a large haematoma and it seems unlikely that ligation of the larger vessels to and from an irreparably damaged limb would do any more than induce more ischaemia, with increased return of potassium to the main circulation through the smaller anastomotic vessels and by diffusion. Radical amputation would therefore have been the only logical procedure in Case 2, and such an operation is a formidable one in an already dangerously ill patient.

Nevertheless, decreasing the source of excess potassium by surgical or medical means is suggested as an essential part of the management of cases of traumatic renal failure with hyperkalaemia.

\section{SUMMARY}

1. Two cases are reported in which hyperkalaemia was a prominent feature in acute renal failure and in which obvious sources of excess potassium were apparent.

2. The literature pertaining to potassium in acute renal failure is briefly reviewed.

3. A return to the surgical elimination of large and expendable tissue sources of potassium in the management of acute renal failure with hyperkalaemia is suggested.

The authors express their thanks to Dr T. R. Harmon for the pathological material and to Dr F. C. Preston for the details of Case 2.

\section{REFERENCES}

Allen, A. C. (1952): The Kidney, p. 72. London: J. and A. Churchill Ltd.

Balch, H. H., Meroney, W. H., and Sako, Y. (1955): Observations on the Surgical Care of Patients with Post-traumatic Renal Insufficiency. Surgery, Gynecology and Obstetrics, 100, 439.

Belsey, R., and McMichael, J. (1942): In Discussion on the Effects on the Kidney of Trauma. Proceedings of the Royal Society of Medicine (Section of Surgery), 35, 321.

Burnett, C. H., Shapiro, S. L., Simeone, F. A., Beecher, H. K., Mallory, T. B., and Sullivan, E. R. (1947): Post-traumatic Renal Insufficiency. Surgery, 22, 994.

Derot, M., Pignard, P., Touraine, R. L., and Bernard, J. (1953): Le potassium dans les néphropathies tubulaires anuriques. Presse Médicale, 61, 207.

Fenn, W. O. (1940): The Rôle of Potassium in Physiological Processes. Physiological Reviews, 20, 377.

Green, H. N. (1945): Biochemical Factors in the Aetiology of " Shock." British Medical Bulletin, 3, 102. 
Hicks, M. H., Crutchfield, A. J., and Wood, J. E., Jun. (1950): Intestinal Lavage in the Potassium Intoxication of Lower Nephron Nephrosis. American Journal of Medicine, 9, 57.

Hoff, H. E., Smith, P. K., and WinkLeR, A. W. (1941): The Cause of Death in Experimental Anuria. Journal of Clinical Investigation, 20, 607.

Humphrey, J. H., and Avery Jones, F. (1947): Oliguria after Abortion. Clinical Science, 6, 173.

Keith, N. M., and Burchell, H. B. (1949): Clinical Intoxication with Potassium: its Occurrence in Severe Renal Insufficiency. American Journal of the Medical Sciences, 217, 1.

Knowles, H. C., Jun., and Kaplan, S. A. (1953): Treatment of Hyperkalemia in Acute Renal Failure using Exchange Resins. Archives of Internal Medicine, 92, 189.

Meroney, W. H., and Herndon, R. F. (1954): The Management of Acute Renal Insufficiency. Journal of the American Medical Association, 155, 877.

MuiRheAD, E. E., and Hill, J. M. (1948): The Treatment of Acute Renal Insufficiency. Surgery, Gynecology and Obstetrics, 87, 445.

Platt, R. (1953): Water and Electrolytes in Renal Failure. Acta Medica Scandinavica, 146, 39.

Rewell, R. E. (1943): Rise in Potassium Concentration in the Blood Stream following Ischaemia of Muscle Masses. British Medical Journal, ii, 483.

Sмiтh, H. W. (1951): The Kidney: Structure and Function in Health and Disease, pp. 348-349, 752-813. New York: Oxford University Press.

Smith, L. H., Jun., Post, R. S., Teschan, P. E., Abernathy, R. S., Davis, J. H., Gray, D. M., Howard, J. M., Johnson, K. E., Klopp, E., Mundy, R. L., O’Meara, M. P., and Rush, B. F., Jun. (1955): Post-traumatic Renal Insufficiency in Military Casualties: II. Management, Use of an Artificial Kidney, Prognosis. American Journal of Medicine, 18, 187.

Stock, R. J. (1949): Acute Urinary Suppression. Observations in Twenty-two Patients. American Journal of Medicine, 7, 45.

Strauss, M. B. (1948): Acute Renal Insufficiency due to Lower Nephron Nephrosis. New England Journal of Medicine, 239, 693.

Swann, R. C., and Merrill, J. P. (1953): The Clinical Course of Acute Renal Failure. Medicine, 32, 215.

Teschan, P. E., Post, R. S., Smith, L. H., Jun., Abernathy, R. S., Davis, J. H., Gray, D. M., Howard, J. M., Johnson, K. E., Klopp, E., Mundy, R. L., O’Meara, M. P., and Rush, B. F., Jun. (1955): Post-traumatic Renal Insufficiency in Military Casualties: I. Clinical Characteristics. American Journal of Medicine, 18, 172. Winkler, A. W., Hoff, H. E., and Smith, P. K. (1941): The Toxicity of Orally Administered Potassium Salts in Renal Insufficiency. Journal of Clinical Investigation, 20, 119. 